counting $(\mathrm{MA}$ ratio $=\mathrm{real} /$ theoretical doses taken $)$. One point $(+1$ point score) was attributed for MA if: Irb $>20 \mathrm{ng} / \mathrm{ml}$ or UR $>4$ $\mathrm{nmol} / \mathrm{mmol}$ or last dose had been taken $<24 \mathrm{~h}$ before visit or MA ratio $>80 \%$. Three $\mathrm{MA}$ levels were assigned: low MA (score $<2$ ), intermediate MA (score +3), and sufficient MA (score + 4).

Results Only 82 patients were sufficiently adherent: 46 and 36 patients among the $\mathrm{AB}$ and $\mathrm{RB}$ groups, respectively. 52 had intermediate MA (23 and 29, respectively); 30 had low MA (13 and 17, respectively) (inter-groups difference NS). Patients with low MA were younger than sufficient MA patients $(50 \pm 11$ vs. $56 \pm 10$ yrs, $p<0.011)$; no difference was ascribed to gender or dASBP $(152 \pm 14$ vs. $148 \pm 12 \mathrm{mmHg}, p=0.16$ ). Other clinical characteristics did not differ except the glomerular filtration rate: lower among adherent patients than low MA patients $(95 \pm 25$ vs. $107 \pm 28 \mathrm{ml} / \mathrm{min}$, $\mathrm{p}<0.02)$

Conclusions We propose a score of $3 \mathrm{MA}$ levels (low, intermediate, sufficient) based on 4 complementary quantitative and qualitative methods. A combination approach is essential to balance imprecision of observed data. There were no differences in major clinical characteristics between groups. Further comparisons into each group of treatment and longer duration of treatment might be necessary to observe a significant differential effect among MA groups. Therapeutic education sessions could be useful for RH patients who undertake complex treatment.

No conflict of interest.

\section{CPC-066 IDENTIFICATION OF PATIENT GROUPS WITH INSUFFICIENT KNOWLEDGE ABOUT THEIR MEDICINES AT HOSPITAL DISCHARGE}

doi:10.1136/ejhpharm-2013-000276.523

${ }^{1} \mathrm{~V}$ Glisic, ${ }^{2} \mathrm{G}$ Jevtic, ${ }^{3} \mathrm{~S}$ Hrgic, ${ }^{4} \mathrm{~V}$ Vucetic, ${ }^{5 B}$ Popovic, ${ }^{6} \mathrm{~S}$ Vezmar Kovacevic, ${ }^{6} \mathrm{M}$ Culafic. 'Zvezdara University Medical Center, Hospital Pharmacy, Belgrade, Serbia; ${ }^{2}$ Clinical Center of Serbia, Hospital Pharmacy, Belgrade, Serbia; ${ }^{3}$ Clinical Center of Vojvodina, Hospital Pharmacy, Novi Sad, Serbia; ${ }^{4}$ Clinical Center of Kragujevac, Hospital Pharmacy, Kragujevac, Serbia; ${ }^{5}$ General Hospital Sabac, Hospital Pharmacy, Sabac, Serbia; ${ }^{6}$ Faculty of Pharmacy, Department of Pharmacokinetics and Clinical Pharmacy, Belgrade, Serbia

Background Hospital patients in Serbia receive information about their medicines from physicians and nurses. Pharmacists are not involved in medicines counselling. In countries with developed health care, pharmacists provide counselling to patients at discharge.

Purpose To establish which groups of hospital patients got the least information about their medicines, since these patients could profit from additional counselling at discharge, provided by pharmacists.

Materials and Methods The study was carried out in five hospitals in Serbia, over a period of 8 weeks. Pharmacists collected clinical data from the patient's medical notes. Patients' knowledge of medicines was assessed through an interview using a structured questionnaire, on the morning of discharge. We evaluated 3 groups of patients according to age, length of hospital stay and number of newly-introduced medicines. They were asked seven questions: if they were informed about all medicines, reasons for treatment, the effects of the drug, duration of treatment, posology and method of administration, undesirable effects and interactions. 'Yes' was awarded two points, 'partially' one and 'no' no points. A total $\leq 10$ of all answers per patient was defined as insufficient knowledge.

Results 148 patients (mean age 60 years) were interviewed. $74 \%$ of patients younger than 65 years and $89 \%$ of elder patients showed insufficient knowledge. Length of hospital stay had impact on patient knowledge. $70 \%$ who stayed more than 20 days had insufficient knowledge vs. $85 \%$ who were hospitalised less than 10 days. Insufficient knowledge increased with number of newly-introduced medicines ( $80 \%$ who had 1 vs. $96 \%$ who had $\geq 5$ new drugs on discharge).

Conclusions The findings of this study indicate that older patients, those who stay less time in hospital and those who receive more new drugs on discharge need to get more counselling about their treatment. Serbian pharmacists can take a proactive role for these patients.

No conflict of interest.

\section{CPC-067 IMPACT OF A MULTIDISCIPLINARY TEAM ON THE PROPER USE OF CARBAPENEMS: BEFORE/AFTER SURVEY AT TENON HOSPITAL}

doi:10.1136/ejhpharm-2013-000276.524

1] Thibault, ${ }^{2} \mathrm{H}$ Cordel, ${ }^{3} \mathrm{~S}$ Vimont, ${ }^{3} \mathrm{C}$ Verdet, ${ }^{4} \mathrm{M}$ Denis, ${ }^{2} \mathrm{G}$ Pialoux, ${ }^{3} \mathrm{G}$ Arlet, II Debrix, ${ }^{1}$ S Guessant. ${ }^{1}$ Hopital Tenon (AP-HP), Pharmacy, Paris, France; ${ }^{2}$ Hopital Tenon (AP-HP), Infectious and Tropical Diseases Department, Paris, France; ${ }^{3}$ Hopital Tenon (AP-HP), Microbiology Department, Paris, France; ${ }^{4}$ Hopital Tenon (AP-HP), Hygiene Department, Paris, France

Background The optimization of antibiotic therapy has become a major issue. Indeed, the evolution of bacterial resistance requires prescribers to reserve use of antibiotics and especially carbapenems. Various bodies have made recommendations to improve antibiotic regimens and thus preserve the effectiveness of these major antibiotics. At Tenon Hospital, a multidisciplinary unit was created in May 2011. It includes clinicians, bacteriologists, hygienists and pharmacists. Meropenem and ertapenem were already controlled whereas imipenem and doripenem were given without restrictions before May 2011.

Purpose To assess the impact of this new organisation, a study compared the requirements for carbapenems before and after the antibiotic management team was created.

Materials and Methods All patients who received at least one dose of carbapenem were included. Bacteriological and biological characteristics of each patient were found. The compliance of each prescription with the available guidelines was assessed studying the duration of treatment, dose and indications. Two periods were defined: the first between January 2009 and September 2010 and the second between June 2011 and May 2012.

Results Duration of the treatment was the single criteria that had changed for ertapenem and meropenem. The impact of this team is greater for the prescriptions of doripenem and imipenem. Establishment of that team shortened the duration of treatment: 2 days for doripenem and 4 days for imipenem. The number of unjustified prescriptions of imipenem decreased from $45 \%$ to $5 \%$ for empirical treatments and from $51 \%$ to $20 \%$ for documented treatments.

Conclusions Reduced length of treatment is important and reduces the selection pressure. This explains why carbapenemresistant bacteria have been isolated only four times in the past year. Results obtained are similar to those obtained in two Parisian hospitals.

No conflict of interest.

\section{CPC-068 IMPACT OF OPTIMISING PRESCRIPTIONS TO REDUCE THE RISK OF FALLS IN ELDERLY PEOPLE}

doi:10.1136/ejhpharm-2013-000276.525

${ }^{1} \mathrm{~S}$ Couderc, 'S Hoang, ' $\mathrm{C}$ Lebaudy, ${ }^{2} \mathrm{M}$ Secher, ${ }^{2} \mathrm{C}$ Hein, ${ }^{2} \mathrm{~F}$ Nourhashemi, ${ }^{1 P}$ Cestac. 'University Hospital, Pharmacy, Toulouse, France; 'University Hospital, Geriatrics, Toulouse, France

Background The increase in life expectancy increases the risk of falls, leading to dependence and death. Some studies have shown a link between inappropriate prescriptions and falls.

Purpose The main objective of this study was to evaluate if we could reduce falls and potentially readmissions by optimising the prescription of drugs in elderly people.

Materials and Methods From May to December 2011, we enrolled patients admitted for falls in a geriatric post-acute care 